\title{
AN ONLINE COURSE IN POWER OBJECT WORKING MODES MODELING AND OPTIMISATION
}

\author{
Vardan Mkrttchian ${ }^{1}$ and Miroljub Kljajic ${ }^{2}$ \\ ${ }^{1}$ All Armenian Internet University \\ P.O.Box 965, Lane Cove, NSW, 2066, Australia \\ ${ }^{2}$ Faculty of Organizational Sciences, University of Maribor \\ Kidričeva 55a, SI-4000 Kranj, Slovenia
}

\begin{abstract}
The paper describes web-based online materials for a course in power object working modes modeling and optimization. The course covers topics like power systems and models, system identification, modeling and optimization, with fuzzy sets theory methods using. An essential part of the material is interactive demos that are implemented with Matlab, Simulink and Matlab Web Server. Copyright ${ }^{\circledR} 2005$ IFAC
\end{abstract}

Keywords: Education, identification, modeling, optimization, fuzzy sets.

\section{INTRODUCTION}

The rapid development of computer and communication technology, especially Internet and World Wide Web, has made a new kind of education possible. Distance learning is supplementing, or even replacing, traditional teaching methods in all educational levels, from primary schools to universities.

In the field of control education both web based remote laboratories (Mkrttchian and Yelchyan, 2004a) and control courses in virtual enterprises (Mkrttchian and Kljajić, 2004) have been introduced. The subject of this paper falls into the latter category. The goal of the course Power objects working modes modeling and optimization is to give readiness to perform tasks involving modeling and optimization of dynamic systems. The course is based on the textbook Modeling and Optimization of Thermal Processes by Mkrttchian, 1999. It is a one-semester course aimed at third year students, and it consists of 32 hours of lectures and 32 hours of computer exercises. The lectures and exercises are once a week and both take two hours at a time. In the computer exercises students learn how to build simulation models for simple dynamic systems using Matlab (Mathworks, 2000a) and Simulink (Mathworks, $2000 \mathrm{~b})$. The purpose of the developed distance learning material is to supplement, not to replace, traditional teaching, using the collaborative learning and new online educational psychology for virtual university (Kljajić, Mkrttchian and Škraba, 2004).

Equipment working modes optimisation is the one of most important problem of energetic enterprises. There are a great number of works in this field, but it is very difficult to reach a desired result, i.e. to create methodical for obtaining about optimal load distribution between station aggregates (subsystems). Fuzzy character of the initial information, which traditionally tries to handle by classical methods, is one of the essential problems here.

Problems of fuzzy sets theory efficiency for solving control task are discussed in significant amount of publication. The main purpose of present work is to develop the methodical aspects of fuzzy methods using and possible approach to using fuzzy information in load distribution between power units problem with taking into account mostly important restrict factors, such as ecological factor.

The course is one of the pilot courses in a Russian office of All Armenian Internet University (Mkrttchian and Petrosyan, 2004a). Its selection as one of the pilot courses was motivated by several reasons. Number of students taking the course is 
usually rather large, typically over fifty. This can be a problem because teaching resources are limited. The course is also in the curriculum of the conversion education program offered by the university. The participants of the program are B.Sc. engineers who aim to upgrade their degree to M.Sc. They are usually working in industry, and thus they often miss lectures and exercises. The third reason was the subject of the course. Because it is a computer-oriented course, it is also a natural test case for new computer-based teaching methods. This paper is organized as follows. Section 2 describes the software architecture of the system and design theory. Section 3 deals with the structure of the course from a content point of view. Feedback from students is summarized in Section 4, and conclusions finish the paper.

\section{SYSTEM ARCHITECTURE AND DESIGN THEORY}

A straightforward way to create a distance learning course is to build a web site consisting of dozens of web pages written in Hypertext Markup Language (HTML). However, this is not an adequate solution for a course like Modeling and Optimization due to two reasons: course material is mathematically oriented and interactive demos are an essential part of the course (Mkrttchian and Petrosyan, 2004b).

\subsection{Mathematics}

Only very simple mathematical equations can be written using HTML. More complex equations are often included as images. However, this is not a flexible solution if the number of equations is large.

Another solution would have been to use Mathematical Markup Language (MathML), which is intended to facilitate the use of mathematical and scientific content on the Web. Unfortunately, MathML is still not a mature technology. This means, for example, that browsers can not render MathML without special plug-ins.

Our solution was to use Adobe Portable Document Format (PDF) when a page includes complex mathematical equations. PDF files can be shared, viewed, navigated, and printed by anyone with free Adobe Acrobat Reader software. PDF is probably the most widely used format for mathematically oriented content on the Web.

\subsection{Dynamic content}

The web pages of the course are partly in HTML, and partly in PDF format. The remaining problem is that these are both formats for static web content.

Dynamic content in the form of interactive demos is important for the course. One can add dynamic content to web pages using languages like Perl, Java, and JavaScript. However, this can take a lot of effort because those are more or less general-purpose languages that do not specifically support modeling and simulation applications.

Recently, solutions have been proposed that make it possible to run Matlab and Simulink applications from web pages (Hassan et al., 1999; Mathworks, 2000c). Matlab and Simulink are widely used and well suited for modelling and simulation.

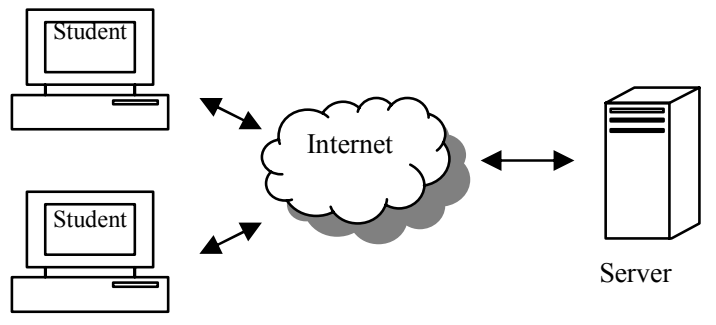

Fig. 1. System architecture

The interactive demos of the Modelling and Simulation course are implemented using Matlab, Simulink and Matlab Web Server software. System architecture is depicted on Fig. 1. Matlab and Matlab Web Server software run on a server. Several copies of Matlab can run concurrently. Students communicate with the server through their web browsers. Students do not need any special software besides a web browser.

Student

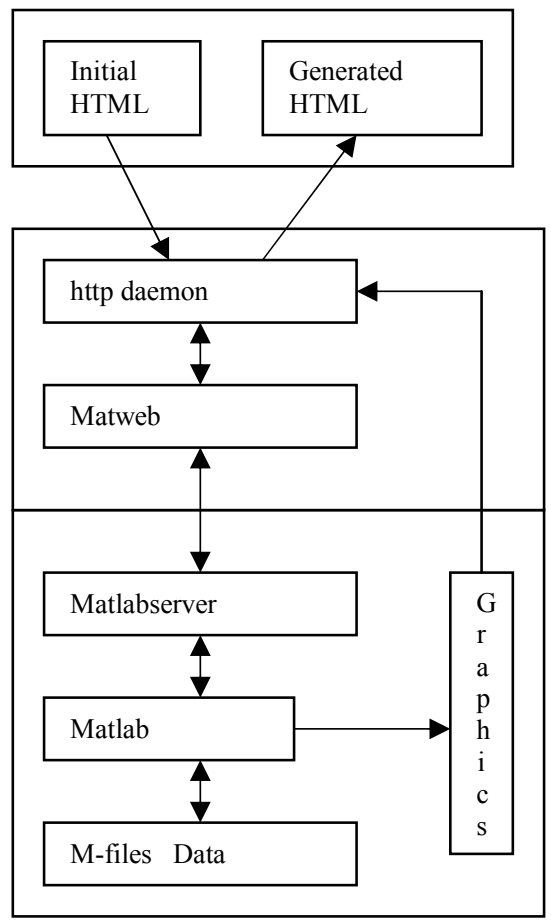

Fig. 2. Communication between student and server

Interactive demos typically consist of two HTML documents and one Matlab M-file. The first HTML document is for collecting data from a user. The data is collected using HTML forms. Then the data is sending to the server, where it is extracted from HTML documents and transferred to a Matlab program (M-file), which performs necessary 
numerical computations. An HTML document containing the results is generated by the Matlab Web Server. This document can contain both text and images. The document is send to the client and displayed in its web browser. Fig. 2 shows how data is moved between the students and the server.

\subsection{Fuzzy sets theory}

Specialist's opinion about possibilities of fuzzy sets theory (FST) in solving the control task spreads from statement that this theory allows to solve any problem of control or management with greater efficiency, than classical methods allow to do this, till the negation of usefulness of FST.

Efficiency of FST methods depends in many on evaluations of the initial information particularities. The methods of FST have not alternative, if at least one of variables in the initial information is fuzzy. By analysis of the modern power station technological process a lot of such information comes to light.

The main reasons for existents of the fuzzy information in technical and economical control problems are:

- absence of possibility to accomplish exact measurements because lack of measurement method or high cost of measurement equipment;

- using indicators instead of exact measurements for system simplification and price reducing;

- complex stochastic nature of variables.

Problem of load sharing between power units of power plant has a significant meaning from economical point of view. In the last time considerable attention is devoted to ecological conditions and reliability of power supply. In the multicriteria optimisation side by side with the reliable quantitative data some evaluations, which were got not as the result of measurements, happens to use. An ecological restrictions (strong, average, weak,) a probability of emergency stopping (small, average, high) are examples of such evaluations. At need of account of these factors, the informal decision can be received with using the expert evaluations, which are based on the data and experience of equipment running.

The procedure of the fuzzy logic conclusion gives opportunity to receive numerical expert evaluation on the base of qualitative initial information.

Evaluation of the power unit load $N_{i}$ with provision for the given total power plant load $N_{\Sigma}$ and, for example, ecological restrictions $E c R$ can be determined on the base of algorithm:

$$
\text { If } N_{\Sigma} \text { and } E c R \text {, then } N_{i}
$$

Ecological restriction $E c R$ is determined as the fuzzy variable and the plant load $N_{\Sigma}$ is (consequence of energy demand) measured value. Measured variables must be converted into fuzzy information for using of the fuzzy method.

Scales definition for the fuzzy variable $E c R$ is the first step in algorithm (1) realization, for example 01 ( 0 - no restriction, 1 - maximal restriction). Next step is the creation of rule base and choosing of membership functions for all variables. This is the weakly formalized task and quality of obtained result is depend essentially on membership functions shape, quantity of terms and base points. All available experimental date, measured values and experts experience must be turn to account for creation of the rule base.

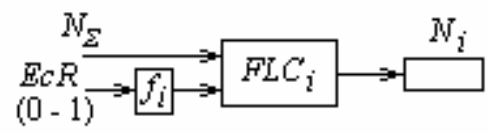

Fig.3. Structure of the fuzzy conclusion module.

An experimental data shove that even the same type of power plant equipment can be characterized by different properties from the point of view of ecological criterion. This difference can be discounted in the procedure of fuzzy logic conclusion (FLC) by some non-linear function $f_{i}$ (in simplest case by coefficient $k_{i}$ ). The algorithm (1) is realized in the fuzzy conclusion module (FCM) (Fig.3 shows the module structure).

The given load of power plant $N_{\Sigma}$ (MWt) and the fuzzy evaluation of an ecological restriction $E c R$ on the scale $0 \ldots 1$ are the module input variables. The output of the module is the value of power unit load satisfying to evaluation of the ecological restriction.

The FCM is the base for developing a decision support system (Fig.4.), which permits to evaluate the loads distribution between power units under ecological restriction.

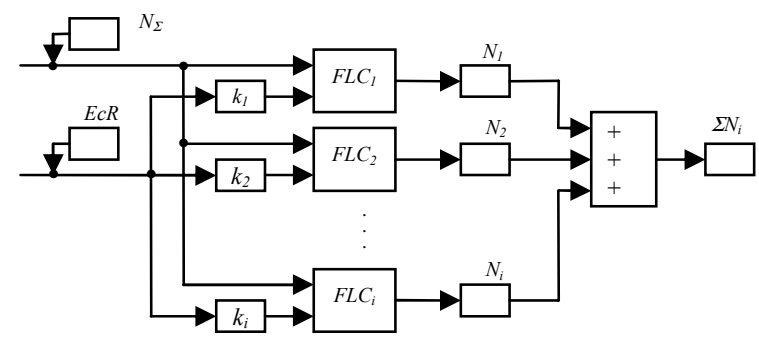

Fig.4. Structure of the decision support system.

The output of each FLC is an evaluation of maximal load of power unit $\mathrm{Ni}$, satisfying to ecological restriction.

Structures, shown in fig. 3 and 4 can be used with necessity in optimisation with other criterion, for example - economical, reliability or manoeuvrability. 


\section{STRUCTURE OF THE COURSE}

Like the book, the course and the web material are divided into four parts:

- Models. The first part deals with typical ways of describing dynamic systems.

- Physical modeling. The second part discusses how to construct a mathematical model from knowledge of the basic mechanisms of a system.

- Identification. The third part deals with methods to arrive at mathematical models from input/output data measured from a system.

- Simulation. The fourth part describes how models are simulated.

- Optimization. The fifth part describes optimization of power object working modes.

\subsection{Models}

Mkrttchian, 1999, shows the navigation map for the first part of the material in textbook Modeling and Optimization of Thermal Processes. Electronic version of this textbook is exhibit to described distance course. Each block represents a model type, and each arrow a transformation between two model types. The upper part of the map describes time continuous models, and the lower part time discrete models. Color codes are used to separate non-linear and linear time domain models and frequency domain models. A student can find information on a model type or transformation by clicking the corresponding block or arrow. Because the material is mathematically oriented including several rather complex equations, the pages giving detailed descriptions of model types and transformations are in PDF format.

\subsection{Physical modeling}

In this part students can go through the different phases of the physical modeling process: structuring the problem, setting up the basic equations and forming the state-space model. The theoretical content of the web pages is very limited because a more detailed presentation is given in the book and lectures. The emphasis is on examples, which go through the phases of physical modeling.

Students can simulate the models created by physical modeling with different parameter values.

The parameter values are sending to the server where Matlab and Simulink are running. Their Matlab runs a simulation and sends the results back to the client where they are displayed in a new browser window.

Simulation results are presented in graphical form, and from these figures a student can easily see how the changes in parameters change the simulation results.

\subsection{Identification}

A navigation map of the identification cycle is the initial page of the identification part. From the map students can easily see the main phases of the cycle and how they depend on each other. The elements of the map work as links to pages, which have more detailed information. The shape of the element tells whether the user (oval) or computer (rectangle) hasthemain role in that phase.

The pages, which have more detailed information of each subject, contain some theory, examples, and interactive demos. The theory covers only the main points of the subject because these questions are covered more thoroughly in the book and lectures.

Also the examples focus on the practical side of identification.

In the interactive demos the user can estimate the impulse response of a system using either transient or correlation analysis. Frequency response estimates can be computed using Fourier or spectral analysis.

Also the most typical parametric models, ARX, ARMAX, OE, and BJ, can be estimated. Interactive demos are also available for a selection of model validation methods: comparison of measured and predicted outputs, residual analysis, comparison of parametric and non-parametric models, pole-zero plots and estimates of parameter uncertainty.

All computations are performed on a server computer, which generates a web page containing the results and sends it to the client computer. Matlab's System Identification Toolbox (Ljung, 2000) is used for computations.

\subsection{Simulation}

The fourth part deals with simulation. The main focus is on numerical integration algorithms. The material covers topics like fixed time step vs. variable time step, one-step vs. multiuse methods, explicit vs. implicit algorithms, low-order vs. highorder methods, and stiff vs. non-stiff differential equations. In interactive demos students can simulate a given system using different numerical integration algorithms, like Euler, Runge-Kutta, and AdamsBashforth. It is possible to use either fixed or variable time steps.

\subsection{Optimization}

The fifth part describes optimization of power object working modes multicriteria optimisation with taking into account valuable information, using of which is impossible by classical approaches due to its fuzzy nature. 


\section{STUDENT FEEDBACK}

During the development of the material feedback was collected from students who had taken the course earlier. That was a good way to find out the main problems and see how different students understand various things in the material. The feedback from testers was very good and they considered the web site to be easy to use. They liked the idea that users can independently choose what they want to do and in which order. Ease of navigation is also considered very important, and this emphasizes the logical structure of the site.

The material was in actual use for the first time during the autumn semester of 2004. Feedback from the students was mainly positive, although some technical problems were encountered. Matlab Web Server occasionally stopped working, which meant that at these times the interactive demos were out of use. This was, naturally, a cause of frustration for some students, although the rest of the material was still available. A summary from the student feedback is that it is a good idea to make some material available on the web, but it is, at least at the moment, impossible to totally replace traditional teaching, like lectures and exercise, with distance learning material.

\section{CONCLUSIONS}

- In the field of education, distance learning can be used in two different ways: it can replace traditional teaching or it can support it. If it replaces the lectures and face-to-face exercises, material has to be large enough and has good composition. Even then, it has to be possible for a student to contact a teacher, for example by email, and ask questions and advice.

- Partly due to limited resources, time and money, a supportive role was chosen for distance learning material in this project. If the education on the Web just supports traditional teaching, there is no need to give all information on the Web. The teachers and students can still meet face to face at the lectures and exercises but the Web is a good extra tool in education.

- The material of the Modeling and Optimization course is mathematically oriented. This meant that the traditional way of building a web site as a collection of web pages written in HTML had to be extended. Static content containing several complex mathematical equations can be easily created and distributed on the Web using the PDF format.

- Dynamic content, like interactive demos, were created using Matlab, Simulink, and Matlab Web Server software. This was considered a more flexible solution than the use of "weboriented" languages, like Java, because Matlab and Simulink are high-level languages that support modeling and simulation extremely well. Because of the supportive role of the material, examples and interactive demos are emphasized in it. It is our opinion that textbooks and traditional lectures are more efficient ways to present theoretical content than the Web.

- Offered paper allow to carry out power objects working modes multicriteria optimization with taking into account valuable information, using of which is impossible by classical approaches due to its fuzzy nature.

\section{REFERENCES}

Copinga, G.J.C., B. De Schutter and J.M.A. Scherpen (2001). A Web-based Study Support Environment for Systems and Control Courses. Proc. of the American Control Conference, 1155-1160.

Hassan, C., R Tuschák, I. Vajk, R. Bars, J. Hetthëssy, F. Kovács and G. Szitnyai (1999). A New Web/Matlab Based System in Control Education, Proc. of the $14^{\text {th }}$ IFAC World Congress, Vol. M, 241 - 246.

Kljajić, M., V. Mkrttchian and A. Škraba (2004). Collaborative Learning and Organizational Concept in Virtual University Education, Proc. of the International Conference of Cognition and Exploratory Learning of Digital Age, 396 - 399. ISBN: 972-98947-7-9.

Lieslehto, L., M. Hakala, and T. Karppinen (2002). Proc. of the $15^{\text {th }}$ IFAC World Congress, Vol. M, $235-239$.

Ljung, L. (2000). System Identification Toolbox for Use with Matlab (Ver. 5). Mathworks.

Mathworks (2000a): Using Matlab (Ver. 6). Mathworks.

Mathworks (2000b): Using Simulink (Ver. 4). Mathworks.

Mathworks (2000c): Matlab Web Server. Mathworks.

Mkrttchian, V. and M. Kljajić (2004). Study Problems of E-Learning and Virtual Enterprises in Online University, Proc. of the $6^{\text {th }}$ International Conference on Systems Research, Informatics and Cybernetics. 49-53. ISBN: 1894613-62-7.

Mkrttchian, V. and E. Petrosyan (2004a). Multiversion Web Servers of Cooperative Work in All Armenian University Network, Proc. of International Conference Advanced Information Technology in Education. 34-38.

Mkrttchian, V. and E. Petrosyan (2004b). Creation of the Web Servers of Joint Work in All Armenian Internet University Network, Proc. of Internet Conference the Information Technology in Science and Education. 41-44.

Mkrttchian, V. and R. Yelchyan (2004a). Using the Virtual Networking Teaching Laboratory in All Armenian Internet University, Proc. of International Conference Advanced Information Technology in Education. 56-60.

Mkrttchian, V. and R. Yelchyan (2004b). Apply to Virtual Networking Teaching Laboratory in All Armenian Internet University, Proc. of the $4^{\text {th }}$ International Scientific Conference on Internet in Education and Science. 80-83. 